IFN Working Paper No. 705, 2007

\title{
Trust and Growth: A Shaky Relationship
}

Niclas Berggren, Mikael Elinder and Henrik Jordahl 


\title{
Niclas Berggren • Mikael Elinder • Henrik Jordahl \\ Trust and growth: a shaky relationship
}

\begin{abstract}
We conduct an extensive robustness analysis of the relationship between trust and growth by investigating a later time period and a bigger sample than in previous studies. In addition to robustness tests that focus on model uncertainty, we systematize the investigation of outlier influence on the results by using the robust estimation technique Least Trimmed Squares. We find that when outliers (especially China) are removed, the trust-growth relationship is no longer robust. On average, the trust coefficient is half as large as in previous findings.
\end{abstract}

Keywords Trust $\bullet$ Growth $\bullet$ Robustness $\bullet$ Social capital $\bullet$ Outliers

JEL Classification $\quad \mathrm{O} 40 \cdot \mathrm{Z} 13$

\section{Introduction}

Numerous studies indicate that generalized trust is beneficial for economic growth - see, e.g., Knack and Keefer (1997), La Porta et al. (1997), Dasgupta and Sergaldin (2000), Glaeser et al. (2000), Zak and Knack (2001) and Beugelsdijk et al. (2004). By generalized trust (henceforth referred to merely as trust) is meant trust in people in general, i.e., trust in people one knows nothing about. Zak and Knack (2001) develop a theoretical model where trust is defined as the time people spend in production rather than in verifying that others do not cheat or behave opportunistically. High-trusting societies are societies in which such transaction costs are low, which is thought to stimulate investment, production and trade, which in turn leads to economic growth. ${ }^{1}$ Beugelsdijk et al. conclude that the relationship between trust and economic growth is highly robust in terms of statistical significance and reasonably robust in terms of the size of the estimated effect. In this article we examine the conclusions of the previous literature by taking the robustness analysis further.

We do this on the basis of the realization that many economic relationships are notoriously unstable. What once appeared true in one place can often look quite different in other places or at a later point in time. We find it important to investigate the stability of previous findings by exposing them to systematic empirical scrutiny.

Here we investigate whether previous results on the trust-growth relationship for the period 1970-1992 hold also for the 1990s. In so doing, we use new data on trust from the fourth version of the World Values Survey (WVS) (Inglehart et al. 2004) and from the Latinobarómetro (2004), as well as new data on growth. This also increases our sample to 63 countries, compared to 29 countries in Knack and Keefer (1997) and 41 in Zak and Knack (2001) and Beugelsdijk et al. ${ }^{2}$ To separate time and sample effects we compare results based on our sample for the period 1990-2000 with results based on the smaller sample, previously studied by Zak and Knack and by Beugelsdijk et al., for the periods 1970-1992 and 1990-2000.

\section{N. Berggren $(\bowtie)$}

The Ratio Institute, P.O. Box 5095, SE-102 42 Stockholm, Sweden

E-mail: niclas.berggren@ratio.se

\section{Elinder}

Department of Economics, Uppsala University, P.O. Box 513, SE-751 20 Uppsala, Sweden

E-mail: mikael.elinder@nek.uu.se

H. Jordahl

IFN, P.O. Box 55665, SE-102 15 Stockholm, Sweden; and the Ratio Institute

E-mail: henrik.jordahl@ifn.se

\footnotetext{
${ }^{1}$ For other results from the literature on the determinants of economic growth, see, e.g., Barro (1991, 1997), Sala-i-Martin (1997), Durlauf and Quah (1999), Temple (1999) and Sturm and de Haan (2005).

${ }^{2}$ Adding new countries is especially relevant since Beugelsdijk et al. report a distinct sensitivity of the results to the countries included in the sample.
} 
We use extreme bounds analysis (EBA) to see how the statistical significance and the size distribution of the estimated coefficients of trust are affected by a systematic variation of the control variables. Furthermore, we provide a methodological extension of the trust-growth literature by using the robust estimation technique Least Trimmed Squares (LTS) to measure the impact of outliers (i.e., observations that deviate from the general pattern). This technique is also combined with EBA. These extensions of previous studies of the trust-growth relationship make it possible to offer a firmer conclusion about its robustness and to improve the prospects of gaining policy-oriented insights.

Our findings show that the trust-growth relationship is less robust than claimed earlier. When removing outliers, not only is the average size of the estimated trust coefficient distinctly lower - it also turns out that the trust coefficient is statistically significant at the 5 percent level in only ten percent of our 1,140 regressions! The lack of robustness is partly connected with the study of a later time period, but mostly depends on the removal of a few outlying observations, especially China.

\section{Robustness, empirical strategy and data}

\subsection{Robustness and empirical strategy}

There is no universally accepted definition of robustness - the concept is multifaceted and continuous rather than dichotomous - which is why most studies in this area incorporate a variety of robustness criteria. ${ }^{3}$ The most basic and perhaps most important way to examine the robustness of a relationship is to see whether it is stable over time. Previous studies have analysed the relationship between trust and growth using data for 1970-1992. In this study we examine the same relationship for the 1990s.

Many results from cross-country growth regressions have been sensitive to changes in the model specification. It has therefore become common to focus on EBA, which looks at the statistical significance and sign of the estimated coefficients. We incorporate these types of tests into our analysis.

However, there are other ways, often overlooked, in which results may be fragile. As pointed out in Rousseeuw and Leroy (1987), OLS estimates are quite sensitive to outliers, i.e., observations that deviate from the linear pattern formed by the majority of the data. ${ }^{4}$ Outliers occur frequently in datasets because of measurement errors, because some observations may be drawn from a different population with a different type of relationship between the variables of interest or because of exceptional but irrelevant events (e.g., earthquakes). ${ }^{5}$ Applying OLS on a dataset contaminated by outliers may result in severely biased estimates. In the extreme case, one single outlier can result in an infinite bias of OLS estimates, i.e., it has a breakdown point of 0 percent. $^{6}$ To deal with this problem, robust regression methods, i.e., methods that have a breakdown point greater than zero, can be applied. By comparing the OLS estimates with robust estimates it is possible to assess the relationship's sensitivity to outliers.

A related way in which results may be fragile concerns the size of the estimated coefficients and how they change as the control variables are varied. We conduct such a study by looking at the distribution of the estimated trust coefficients. The rationale for this type of test, following McCloskey (1985), McCloskey and Ziliak (1996), Florax et al. (2002) and Ziliak and McCloskey (2004), is that whereas the statistical significance of an estimated coefficient is used for establishing the existence of a relationship between two variables, the real-world relevance of a relationship depends on the size of the estimate. We investigate such matters thoroughly.

\footnotetext{
${ }^{3}$ See Florax et al. (2002).

${ }^{4}$ Such points may have an unusual value for the dependent variable, for a regressor or for both.

${ }^{5}$ Outliers may also occur on legitimate grounds and contain variation that should be included in the estimations. The problem is that there is often no way of knowing when this is the case.

${ }^{6}$ For a technical definition of "breakdown point", see Rousseeuw and Leroy (1987, p. 9).
} 
Furthermore, results may be fragile in other ways, e.g., with respect to different measures of relevant variables ${ }^{7}$. Hence, there are many dimensions in which results may or may not be robust. To make an overall judgement, all the dimensions must be assessed and weighed against each other, and the conclusions must be based on informed judgement rather than a simple check of whether a certain test is passed.

In line with this, our robustness analysis of the data for the 1990s consists of three main parts. First, we apply the robust estimation technique LTS, a novel approach to assess the robustness of the trust-growth relationship. ${ }^{8}$ This technique was pioneered by Rousseeuw (1984) and is described and advocated by, e.g., Temple (1999), Zaman et al. (2001) and Sturm and de Haan (2005). The idea is to use a method that is "robust against the possibility that one or several unannounced outliers may occur anywhere in the data" (Hubert et al. 2004, p. 1515) by, in this case, fitting the majority of the data and identifying outliers as the cases with large residuals.

Outliers are defined on the basis of the following procedure, as outlined in Rousseeuw and Leroy (1987). First, the 75 percent of the observations that give the best fit (that minimize the sum of the squared residuals) are identified and used to calculate a regression line. Then the remaining 25 percent of the observations are added, and their residuals are computed from the fitted values of the first-stage regression. Countries with a standardized residual above a certain value, approximately 2.5 , are identified as outliers. ${ }^{9}$ This procedure concentrates on the observations that best approximate the model to be estimated. After this identification, Reweighted Least Squares (RLS) is used for inference by giving outliers the weight zero and other countries the weight one. The advantage of LTS compared with single-case diagnostics like Cook's distance and DFITS is that it can handle cases with several jointly influential outliers. As we use LTS with a breakdown point of 25 percent, the method can handle cases where up to 25 percent of the observations are jointly influential. ${ }^{10}$

We think that the conclusion in Beugelsdijk et al. (2004), that the size of the trust-growth relationship depends on which countries are included in the sample, makes the systematic LTS/RLS procedure very valuable. Also, it is quite unlikely that the additional countries are perfectly representative for the population of all countries. ${ }^{11}$

Second, we investigate robustness with respect to model specification. Following Leamer (1985), Levine and Renelt (1992), Sala-i-Martin (1997) and Sturm and de Haan (2001), who point out that results of cross-country growth regressions need to be tested in this fashion, we investigate the sensitivity of the statistical significance of trust when the control variables are varied. We look at four tests:

(i) the strong extreme bounds test (indicating whether all of the estimated coefficients are statistically significant at the 5 percent level and of the same sign),

(ii) the weak extreme bounds test (indicating whether at least $95 \%$ of the estimated coefficients are statistically significant at the 5 percent level and of the same sign), ${ }^{12}$

(iii) the strong sign test (indicating whether all of the estimated coefficients have the same sign), and

\footnotetext{
${ }^{7} \mathrm{We}$ do not investigate robustness with respect to the measure of trust. Although our survey-based measure is obviously far from perfect, as pointed out by, e.g., Glaeser et al. $(2000$, pp. 811,815$)$, no alternative measure is available for a large number of countries.

${ }^{8}$ Zak and Knack (2001, p. 310) use some form of robust estimator to downweight cases with large residuals, but it is not clear how this is done.

${ }^{9} 2.5$ is the critical value for the studentized residuals with a confidence interval of 99.5 percent.

${ }^{10}$ For practical-technical information about the LTS estimator and its application, see Verboven and Hubert (2005) and Rousseeuw and Van Driessen (2006).

${ }^{11}$ As data become available for more countries two problems arise. First, results from cross-country regressions are generally first found for a small but relatively homogeneous group of countries (such as the OECD). By adding countries, the heterogeneity between countries increases. When the heterogeneity becomes large it may be reasonable to treat different groups of countries as belonging to different populations. Second, the risk of measurement errors probably increases, since it is usually rich countries with high-quality statistical services that are included first.

${ }^{12}$ We do not use the weighted weak extreme bounds test or the cumulative density function test, following a critique of the weighted EBA expressed by Sturm and de Haan (2002). As shown by them, the varying number of observations in the regressions due to missing observations is problematic. First, the goodness-of-fit measure that is obtained may not be a good indicator of the probability that a model is true. Second, the weights constructed in this way are not equivariant for linear transformations of the dependent variable.
} 
(iv) the weak sign test (indicating whether at least 95 percent of the estimated coefficients have the same sign).

The basic idea of EBA, following Leamer (1985), is to systematically vary certain control variables to see what happens to the statistical significance of the estimates of the variable of interest. A regression equation of the following kind is used (in country i):

$$
\Delta \mathrm{Y}_{\mathrm{i}}=\alpha+\boldsymbol{\beta} \mathbf{F}_{\mathrm{i}}+\gamma \mathrm{x}_{\mathrm{i}}+\boldsymbol{\delta} \mathbf{C}_{\mathrm{i}}+\mathrm{u}_{\mathrm{i}}
$$

where $\Delta Y_{\mathrm{i}}$ refers to growth in GDP per capita, where $\mathbf{F}_{\mathrm{i}}$ is a vector with the fixed variables that are always included in the regressions, where $\mathrm{x}_{\mathrm{i}}$ refers to the variable of interest (trust in our case), where $\mathbf{C}_{i}$ is a vector with three variables from the set of switch variables, and where $u_{i}$ is an error term. We investigate the effects on the statistical significance of $\gamma$ when varying $\mathbf{C}$. This is done by including three switch variables at a time in all possible combinations (which has become the standard way of conducting this kind of test) and using data for up to 63 countries for the 1990s. ${ }^{13}$

We also investigate how the size of the estimated trust coefficient changes as the switch variables are varied. To enable a broad assessment, we provide histograms of the distributions of all estimated trust coefficients; and we report the mean and the median of the estimated coefficients, as well as standard deviations.

Third, we combine the LTS/RLS approach with EBA by identifying outliers in each individual regression and by removing them before conducting the model-uncertainty analysis. ${ }^{14}$ This enables us to see if the extreme bounds tests are passed by the countries that are not identified as outliers. A disadvantage of applying LTS for each regression is that it changes the sample from one regression to another. However, due to missing observations for a few variables, the sample changes anyway when performing the EBA.

\subsection{The data ${ }^{15}$}

This study compares results based on the sample used by Zak and Knack (2001) and Beugelsdijk et al. with results based on our sample of 63 countries, which encompasses new data, not least from the fourth version of the WVS. Henceforth we refer to our sample as the "large sample". The robustness tests are carried out for the small sample of countries used in previous studies both for the period 1970-1992 and for the period 1990-2000, as well as for our large sample for the period 1990-2000. The most recent trust data that we use have not been included in the previous studies. The small and the large sample are briefly described in Table 1.

Table 1 The two samples

\begin{tabular}{|c|c|c|}
\hline Name of sample & Small & Large \\
\hline Countries & 39 & 63 \\
\hline Time period & 1970-1992 and 1990-2000 & 1990-2000 \\
\hline Source for Trust & $\begin{array}{l}\text { Inglehart et al. (2000), Inglehart et al. } \\
\text { (2004) }\end{array}$ & $\begin{array}{l}\text { Inglehart et al. (2000), Inglehart et al. } \\
\text { (2004), Latinobarómetro (2004) }\end{array}$ \\
\hline
\end{tabular}

Our small sample corresponds to that in Zak and Knack (2001) and Beugelsdijk et al., but there the number of countries is 41 (Luxembourg and Nigeria are not included in our small sample due to a lack of data on Schooling). The countries are specified in Table A2.

The variables are divided into four groups: the dependent variable, the variable of interest (Trust), the fixed variables, and the switch variables. The fixed variables are control variables that are

\footnotetext{
${ }^{13}$ Recently, robustness tests based on Bayesian analysis have been proposed and used - see e.g. Fernandez et al. (2001) and Sala-i-Martin et al. (2004). However, we choose not to use such tests here in spite of their advantages (fixed variables are not used and the number of explanatory variables can be varied). As pointed out be Sturm and de Haan (2005), they also have drawbacks, such as the need for a balanced data set (which would severely limit the number of countries or variables that we could include) and not taking outliers or parameter heterogeneity into account.

${ }^{14}$ We wish to thank a referee for suggesting this way of combining LTS/RLS and EBA.

${ }^{15}$ Our dataset can be downloaded from any of our web sites and is also available upon request.
} 
included in all regressions, whereas the switch variables are included and varied when we investigate robustness with respect to model specification. We list the four groups below. Descriptive statistics and sources for all variables can be found in Table A1 in the Appendix. Values for Trust and Growth are listed in Table A2 in the Appendix.

(i) Dependent variable (1): Growth: annual growth of real GDP chain per capita, 1990$2000 .^{16}$

(ii) Variable of interest (1): Trust: the percentage of respondents in each country agreeing with the statement "most people can be trusted" rather than with the alternative "you can't be too careful in dealing with people" (earlier versions of the WVS) or "you need to be very careful in dealing with people" (the latest, fourth version of the WVS). The WVS has been conducted in 1981, 1990-91, 1995-96, and 1999-2002. For each country, we use the first non-missing value in the three latest versions of the WVS. We include additional values for Greece from the Eurobarometer survey and for New Zealand from a government survey; ${ }^{17}$ in addition, we add values from eight Latin American countries for 1995 from the Latinobarómetro (2004). ${ }^{18,19}$

(iii) Fixed variables (3): Schooling: the average number of years in school, 1990; Investmentgood price, the price level of investment; Real GDP per capita, in thousands of USD, 1990.

(iv) Switch variables (20): Control variables that are included in all possible combinations of three.

How were the fixed variables and the switch variables chosen? Generally, they have all been advanced as potential determinants of growth on theoretical grounds, as measures of a possible convergence effect and of human and physical capital. But so have other variables. To make our results as comparable as possible we choose not to deviate from Beugelsdijk et al. and therefore use these three fixed variables. ${ }^{20}$

As for the switch variables, we started with the full set of the Beugelsdijk et al. variables and then implemented some changes on the following grounds. We have removed a few variables for three reasons: poor data, moving forward the time period under study, and avoiding reducing the sample size too much. We have also exchanged some variables, as we believe we have found better data. In total, 68 potential switch variables are in our original dataset. Out of these the 20 listed in Table A1 in the Appendix were chosen, as they have a correlation coefficient with Trust of less than 0.25 in

\footnotetext{
${ }^{16}$ We have also carried out the whole analysis using the estimated growth trend for the same period as the dependent variable. This variable is less sensitive to the choice of start and end years, but it does not measure actual growth rates, which is a drawback. The results are available upon request and without exception close to the ones we present.

${ }^{17}$ See Zak and Knack (2001, p. 307).

18 The Latinobarómetro survey question is consistent with the one from Inglehart et al. (2004). It is formulated thus (in Spanish): "Hablando en general, ¿Diría Ud. que se puede confiar en la mayoría de las personas o que uno nunca es lo suficientemente cuidadoso en el trato con los demás?"

${ }^{19}$ The questions were identical in all these surveys. Whilst we cannot rule out a framing effect - i.e., that the replies to the identical questions differed because of differences between the surveys overall - we think this risk is small. To check this, we compared the Trust measures for 1995 for the nine countries in the Latinobarómetro that are also included in the World Values Survey. Although the mean of Trust in these countries is a bit higher in the Latinobarómetro (19.6) than in the WVS (15.2), the difference is not statistically significant. In the WVS itself there is a similar, small risk that the comparability between countries is not perfect, stemming from the fact that the questions are asked in different languages which may entail different interpretations of certain terms (such as "most people").

${ }^{20}$ These variables are also used by Knack and Keefer (1997) and Zak and Knack (2001). They have also been linked to economic growth in several empirical studies, but naturally, other variables could have been included as well. Cf. Barro (1991), Levine and Renelt (1992), Temple (1999, 2001) and Sturm and de Haan (2005). If one were to replace one of the fixed variables, the most obvious candidate in our view is Investment-good price, which would then be exchanged for Investment share of GDP. The latter measure was used by Zak and Knack (2001) in addition to Investment-good price. The argument against using it is that it can be expected to be endogenous with respect to growth. In any case, as a sensitivity analysis, we have replaced Investment-good price with Investment share of GDP in our analysis. We find that this replacement has a rather small effect on the results. They are a bit more robust, but far from meeting general robustness criteria in EBA or LTS/RLS. As an alternative measure of another of the fixed variables, Real GDP per capita, we have used its natural logarithm, in line with some previous studies. However, this measure is not statistically significant in our basic regression, $\mathrm{R}^{2}$ falls sharply and the Trust estimate is decreased only marginally.
} 
absolute value. This procedure limits the problem of multicollinearity and increases comparability (cf. Beugelsdijk et al., pp. 123-124). ${ }^{21}$ To make sure that our results do not critically depend on this restriction, we also use all 68 switch variables in the EBA in Section 3.3.

One thing that should be pointed out is that because the data we use for the countries not included in previous studies are relatively new, from 1995 and 2000, it stems from the end of the period for which our dependent variable is measured. As in previous studies, there may be a problem of reverse causality. However, we think that the risk of this being more problematic in our study is rather small, since we obtain similar results when only using the countries looked at in Beugelsdijk et al. as when using the large sample (see the following Section).

\section{Robustness results}

This Section presents the results of several robustness tests. ${ }^{22}$ First, we present basic OLS regressions for our two samples (3.1). This is followed by regression results when outliers are deleted, through the application of the robust estimation technique LTS in conjunction with RLS (3.2). Then EBA, focusing on the sign of the estimated Trust coefficient and its statistical significance, is applied (3.3), and it is followed by a combination of LTS and EBA (3.4). Lastly, we investigate how the size and precision of the Trust coefficient respond to changes in the model specification and to changes in the sample (3.5).

\subsection{Basic regressions for two samples}

It is useful to first take a look at the results from basic OLS regressions for the two samples of countries, as reported in Table 2. For the small sample we present estimates both for the 1990s and for 1970-1992, the period studied by Zak and Knack (2001) and Beugelsdijk et al. (2004). The regressions all contain the variable of interest, Trust, as well as the three fixed control variables.

Table 2 Basic regressions (OLS)

\begin{tabular}{llll}
\hline \multicolumn{3}{c}{ Dependent variable: Growth } \\
\hline \multirow{3}{*}{ Trust } & Small sample 1970-1992 & Small sample 1990-2000 & Large sample 1990-2000 \\
& $0.064^{* * *}$ & $0.046^{*}$ & $0.062^{* * *}$ \\
Real GDP per capita & $(0.019)$ & $(0.024)$ & $(0.019)$ \\
& -0.114 & $-0.184^{*}$ & $-0.154^{* *}$ \\
Investment-good price & $(0.105)$ & $(0.074)$ & $(0.064)$ \\
& $-0.041^{* * *}$ & -0.004 & 0.015 \\
Schooling & $(0.011)$ & $(0.018)$ & $(0.009)$ \\
& -0.018 & 0.282 & 0.134 \\
Number of observations & $(0.154)$ & $(0.176)$ & $(0.155)$ \\
\hline
\end{tabular}

Standard errors in parentheses. All estimated equations include a constant term not reported here. Sources and variable definitions: see Table A1. Sample list: see Table A2. For the period 1970-1992 we use the earliest available observation of Trust from the WVS, and values from 1970 for the three control variables.

*significant at $10 \% ; * *$ significant at $5 \% ; * * *$ significant at $1 \%$

The OLS results from the basic model specification point to both a statistically significant and economically important relationship between trust and growth in the 1990s for both samples. ${ }^{23}$ For the small sample, this is the case both for 1970-1992 and for the 1990-2000 period. The estimated trust coefficient for the small sample and the period 1970-1992 is almost a perfect replication of the same

\footnotetext{
${ }^{21}$ Furthermore, looking at the correlation coefficients between the switch variables, these are everywhere quite low (only above 0.5 in one case and distinctly lower in almost all other cases).

${ }^{22}$ The results presented here, as in other cross-country studies, must be interpreted with caution and should only be interpreted as suggesting the possibility of a causal relationship. The results have been obtained using Stata, GAUSS for EBA and MATLAB with the LIBRA package for LTS. All results and calculations in this Section are available upon request.

${ }^{23}$ If we exclude the countries with data on Trust from the Latinobarómetro, the empirical results are very similar to what we obtain for the large sample. This is the case throughout this article.
} 
estimate in Beugelsdijk et al, which is 0.061 (in their Table 2). For the later time period, the size and the statistical significance of the Trust coefficient are greater in the large than in the small sample. When the large sample is considered, an increase in the share of people who believe that most people can be trusted by 10 percentage units entails an increased annual growth rate of 0.62 percentage units. ${ }^{24}$ Of the fixed variables, Real GDP per capita (1990-2000) and Investment-good price (19701992) exhibit statistically significant relationships with Growth, while Schooling never attains statistical significance. ${ }^{25}$ Let us now see how these basic results stand when we expose them to different robustness tests.

\subsection{Least trimmed squares}

We begin by investigating how outliers influence the results. As pointed out above, the previous literature lacks a systematic usage of such robust estimation techniques, an omission which we consider quite serious. Hence, we apply LTS in conjunction with RLS for inference in order to examine the impact of outliers.

Table 3 shows the results for the basic model, with Trust and the three fixed variables as control variables. The first column is based on the small sample, and the ensuing columns are in each case based on a gradual elimination of outliers on the basis of the procedure outlined in Section 2.1.

Table 3 LTS and RLS, small sample, 1990-2000

\begin{tabular}{|c|c|c|c|c|c|c|c|c|}
\hline \multirow{2}{*}{ Trust } & \multicolumn{8}{|c|}{ Dependent variable: Growth } \\
\hline & $\begin{array}{l}0.046^{*} \\
(0.024)\end{array}$ & $\begin{array}{l}0.036 \\
(0.022)\end{array}$ & $\begin{array}{l}0.033 \\
(0.021)\end{array}$ & $\begin{array}{l}0.027 \\
(0.020)\end{array}$ & $\begin{array}{l}0.028 \\
(0.019)\end{array}$ & $\begin{array}{l}0.026 \\
(0.017)\end{array}$ & $\begin{array}{l}0.025 \\
(0.015)\end{array}$ & $\begin{array}{l}0.032 * * \\
(0.014)\end{array}$ \\
\hline $\begin{array}{l}\text { Number of } \\
\text { observations }\end{array}$ & 39 & 38 & 37 & 36 & 35 & 34 & 33 & 32 \\
\hline Sample & Small & $\begin{array}{l}\text { Excl. } \\
\text { Ireland }\end{array}$ & $\begin{array}{l}\text { Excl. } \\
\text { Ireland } \\
\text { Taiwan }\end{array}$ & $\begin{array}{l}\text { Excl. } \\
\text { Ireland } \\
\text { Taiwan } \\
\text { Dom. Rep. }\end{array}$ & $\begin{array}{l}\text { Excl. } \\
\text { Ireland } \\
\text { Taiwan } \\
\text { Dom. Rep } \\
\text { Chile }\end{array}$ & $\begin{array}{l}\text { Excl. } \\
\text { Ireland } \\
\text { Taiwan } \\
\text { Dom. Rep } \\
\text { Chile } \\
\text { Venezuela }\end{array}$ & $\begin{array}{l}\text { Excl. } \\
\text { Ireland } \\
\text { Taiwan } \\
\text { Dom. Rep } \\
\text { Chile } \\
\text { Venezuela } \\
\text { S. Korea }\end{array}$ & $\begin{array}{l}\text { Excl. } \\
\text { Ireland } \\
\text { Taiwan } \\
\text { Dom. Rep } \\
\text { Chile } \\
\text { Venezuela } \\
\text { S. Korea } \\
\text { Argentina }\end{array}$ \\
\hline
\end{tabular}

Standard errors in parentheses. All estimated equations include a constant term and three fixed variables not reported here. We eliminate countries in the descending order of their standardized residuals computed from the fitted values of the firststage regression. Countries with a standardized residual greater than 2.5 are eliminated in this procedure.

*significant at $10 \% ; * *$ significant at $5 \%$; ** significant at $1 \%$

Sources and variable definitions: see Table A1. Sample list: see Table A2.

As can be seen, Ireland is identified as the largest outlier, and its removal reduces the estimated Trust coefficient from 0.46 to 0.036 and renders it statistically insignificant. The gradual elimination of outliers identified by LTS leads to an estimated and statistically significant coefficient of 0.032 , almost half the original size. We have also applied the LTS/RLS procedure on the small sample for the period 1970-1992 with a similar result. When removing five identified outliers, the Trust coefficient drops from 0.064 to 0.026 but remains statistically significant at the 10 percent level.

In Table 4, the corresponding results for the large sample are reported. There, four countries are removed, starting with China, the country with the largest standardized residual.

\footnotetext{
${ }^{24}$ Trust appears quite stable in most countries, but it may still be affected by various factors. Among the proposed determinants are income inequality, ethnic fractionalization, the quality of the legal system, and education. See e.g. Zak and Knack (2001), Alesina and La Ferrara (2002), Knack and Zak (2002) and Berggren and Jordahl (2006).

${ }^{25}$ There seems to be no partial correlation between Investment-good price and Growth for 1990-2000. The same result is obtained if we instead use Investment share of GDP in the regressions. The choice of investment variable - and even its complete exclusion - only has a small impact on the Trust coefficient in any case. As for Schooling, Lorgelly and Owen (1999), Krueger and Lindahl (2001); Temple (2001) and de La Fuente and Domenech (2006) likewise find that the relationship between education, be it male or female, and growth is seldom statistically significant. There are indications that this lack of significance is likely driven by measurement error.
} 
Table 4 LTS and RLS, large sample, 1990-2000

\begin{tabular}{llllll}
\hline \multicolumn{7}{c}{ Dependent variable: Growth } & & & \\
\hline Trust & $0.062^{* * *}$ & $0.039^{*}$ & $0.033^{*}$ & $0.035^{*}$ & $0.032^{*}$ \\
& $(0.019)$ & $(0.020)$ & $(0.019)$ & $(0.019)$ & $(0.018)$ \\
$\begin{array}{l}\text { Number of } \\
\text { observations }\end{array}$ & 63 & 62 & 61 & 60 & 59 \\
Sample & Large & Excl & Excl & Excl & Excl \\
& & China & China & China & China \\
& & Ireland & Ireland & Ireland \\
& & & Nicaragua & Nicaragua \\
\end{tabular}

Standard errors in parentheses. All estimated equations include a constant term and three fixed variables not reported here. We eliminate countries in the descending order of their standardized residuals computed from the fitted values of the firststage regression. Countries with a standardized residual greater than 2.5 are eliminated in this procedure.

*significant at $10 \% ; * *$ significant at $5 \% ; * * *$ significant at $1 \%$

Sources and variable definitions: see Table A1. Sample list: see Table A2.

Table 4, like the previous one, clearly suggests that outliers do affect our results. Removing China, Ireland, Nicaragua and Latvia halves the size of the estimate and sharply reduces the degree of statistical significance, indicating that OLS results may be misleading or, at least, that they should be interpreted carefully.

China and Ireland have Trust scores well above the average, in China's case around 60 percent, and both countries have reported exceptional growth rates. Both countries reappear in Section 3.4 as frequent outliers, with China clearly being the most distinct one. We do not know for certain why China's effect on the results is so large. It may be because of measurement error, because China belongs to a different population than the other countries or because some exceptional but irrelevant events have taken place there. ${ }^{26}$ Bjørnskov (2007) finds that China is an outlier when it comes to Trust: in fact, it is found to have a Trust level that is about 35 percentage points higher than what is predicted by a baseline specification that explains about half of the cross-country variation. ${ }^{27}$ This may point to measurement error as a plausible explanation. There are also some indications that China's growth figures are not entirely credible. ${ }^{28}$ Another possible explanation is cultural. Inglehart (1999) points at Confucianism as a particular type of influence. Renquin is an honor code that entails a negative attitude towards being in debt, both socially and financially, which Buchan and Croson (2004) see as a special and important influence on cooperation and trust. Guanxi denotes personal networks that, according to King (1991), also fill an important function for cooperation and interpersonal trust. ${ }^{29}$ As for Ireland, it shows exceptional growth figures without a corresponding foundation in its trust levels. Institutional reforms, rather than trust, probably explain large parts of the growth record.

However, even with all four outliers removed, the Trust estimate is still economically significant and retains statistical significance at the 10 percent level. For the great majority of the countries, this indicates that an increase in Trust with 10 percentage units is associated with an increased annual growth rate of 0.32 percentage units on average. Although this is certainly not negligible, it is considerably less compared to what previous studies find. ${ }^{30}$

\footnotetext{
${ }^{26}$ In any case, we think that an important benefit of the LTS/RLS method is its transparency: irrespective of the reason for there being outliers like China, it is clear that this particular country tilts the regression line quite a bit.

${ }^{27}$ The same point is made by Uslaner $(2002$, pp. 220, 226): "I eliminated China, since its trust score is suspiciously high. ... I see the Chinese figure as a likely outlier that might reflect the hazards of conducting survey research in a country that Freedom House places at the bottom of its rankings on both political and civil liberties."

${ }^{28}$ See Ren (1997), Maddison (1998), Rawski (2001). The former two point at shortcomings in the data-collection process as the explanation, whereas the latter argues that there has been a systematic falsification of growth figures where lower-level officials have exaggerated in order to impress superiors. Things seem to have improved in later years (Holz, 2003), but throughout the 1990 s, there seems to have been problems.

${ }^{29}$ Previous studies on the trust-growth relationship, such as Knack and Keefer (1997), Zak and Knack (2001) and Beugelsdijk et al., do not include China in their samples.

${ }^{30}$ A referee suggested that the financial crises in South Korea, Indonesia, Brazil and Argentina might have affected the trustgrowth relationship, and to test this we have included a "financial-crisis" dummy variable in the basic regression (reported in Table 2) for the large sample, taking the value 1 for these countries and 0 for all others. The results indicate that Trust is still statistically significant at the 1 percent level, that its estimated coefficient increases marginally to 0.065 and that the four countries on average grew 2.7 percentage points faster per year than the other countries in the period under study.
} 


\subsection{Extreme bounds analysis}

We continue the robustness analysis by looking at the sign and the statistical significance of Trust as the set of control variables is varied in a systematic way. The results are found in Table 5. They are based on the basic regressions in Table 2, with the addition of all possible combinations of three switch variables, which gives a total of 1,140 regressions. Again, the results are presented for two different samples of countries.

Table 5 Robustness results with respect to model specification for two samples, 1990-2000

\begin{tabular}{lll} 
Table 5 Robustness results with respect to model specification for two samples, & 1990-2000 \\
\hline & Small sample & Large sample \\
Share of regressions where Trust is statistically significant at & $29.3 \%$ & $49.3 \%$ \\
the 5 percent level & & 0 \\
$\begin{array}{l}\text { Number of regressions where Trust takes a negative sign } \\
\text { Number of observations }\end{array}$ & 0 & 0 \\
\hline
\end{tabular}

Three switch variables out of 20 are included in each regression. Number of regressions in each column: 1,140. Sources and variable definitions: see Table A1. Sample list: see Table A2.

How robust, then, is the statistical significance of Trust with regard to the model specification? We look at the four robustness tests listed in Section 2.1. First, the strong extreme bounds test is not passed for any of the samples: for neither of them is a 100 percent statistical significance share obtained at the 5 percent level. Second, the same is true for the weak extreme bounds test: for neither of the samples is a 95 percent statistical significance share obtained at the 5 percent level. Third, the strong sign test is passed for both samples, as all estimated coefficients have the same, positive sign. Fourth, and by necessity, so is the weak sign test.

Compared to Beugelsdijk et al., where the weak extreme bounds test was passed, our results again point at a distinctly less robust relationship between Trust and Growth. While Beugelsdijk et al. report a 99.9 percent significance share for Trust at the 5 percent level, we report a much lower figure, 29.3 percent for the same sample. We have replicated the Beugelsdijk et al. finding: for the small sample and the period 1970-1992, we find a 99.3 significance share for Trust at the 5 percent level. In this undertaking, we used our set of switch variables, with one exception: Language fractionalization and Religious fractionalization are replaced by the variable Ethnolinguistic fractionalization, as defined in Beugelsdijk et al. ${ }^{31}$ This replication indicates that the lower robustness in this dimension is due to a later time period.

\subsection{Extreme bounds analysis without outliers}

Here, we combine LTS and EBA. The results are again based on 1,140 regressions. For each regression outliers are uniquely identified and removed. Table 6 contains the results of this undertaking.

\footnotetext{
${ }^{31}$ We have also conducted a corresponding test using all 68 switch variables, which resulted in 50,116 regressions. The significance share for the small sample is then 22.3 percent; and it is 32.3 percent for the large sample. As expected, these shares are lower when additional variables that are more highly correlated with Trust are included. Of the four tests, only the weak sign test is passed - and it is passed for both samples of countries.
} 
Table 6 Robustness results with respect to model specification combined with LTS and RLS

\begin{tabular}{|c|c|c|c|}
\hline & Small sample, 1970-1992 & Small sample, 1990-2000 & Large sample, 1990-2000 \\
\hline $\begin{array}{l}\text { Share of regressions where Trust is } \\
\text { statistically significant at the } 5 \text { percent level }\end{array}$ & $10.5 \%$ & $0.7 \%$ & $10.1 \%$ \\
\hline Mean value of Trust estimates & 0.035 & 0.032 & 0.027 \\
\hline Negative Trust estimates & 0 & 1 & 26 \\
\hline Average number of outliers & 3.0 & 4.1 & 3.9 \\
\hline Minimum number of outliers & 0 & 2 & 1 \\
\hline Maximum number of outliers & 7 & 7 & 8 \\
\hline Number of observations & $32-38$ & $31-37$ & $39-62$ \\
\hline Most frequent outliers (percent of & South Korea $(56 \%)$ & Ireland $(59 \%)$ & China $(43 \%)$ \\
\hline \multirow[t]{4}{*}{ regressions where the country is outlier) } & Taiwan $(48 \%)$ & Dominican Rep. (53\%) & Ireland $(27 \%)$ \\
\hline & Japan $(39 \%)$ & Chile $(47 \%)$ & Chile $(22 \%)$ \\
\hline & Peru $(32 \%)$ & Uruguay (37\%) & Latvia $(20 \%)$ \\
\hline & Switzerland (28\%) & India $(36 \%)$ & Czech Rep (20\%) \\
\hline Number of countries that are never outliers & 9 & 7 & 9 \\
\hline
\end{tabular}

Three switch variables out of 20 are included in each regression. Number of regressions in each column: 1,140 .

Sources and variable definitions: see Table A1. Sample list: see Table A2.

As can be seen in Table 6, the robustness of the trust-growth relationship is dramatically reduced when outliers are removed - in fact, it disappears by any reasonable standard. ${ }^{32}$ By removing outliers identified by the LTS procedure, both the share of statistically significant estimates at the 5 percent level as well as the size of the estimates are reduced. For the large sample, the share of statistically significant estimates is reduced to 10.1 percent. The corresponding figure for the small sample is as low as 0.7 percent. For the small sample and the period 1970-1992, this share of statistically significant estimates of Trust is 10.5 percent. Robustness with regard to empirical specification is heavily influenced by outliers also for this period. China is the most extreme outlier in the large sample (it is not included in the small sample), and by excluding China from all regressions the share of statistically significant estimates falls from $49.3 \%$ to $13.2 \%$ and the mean size of the estimates falls from 0.044 to $0.033 .{ }^{33}$ It is only by including China that it is possible to get results that indicate a reasonably robust relationship for the 1990s (but even then, the degree of robustness is low by conventional standards).

We conclude by noting that the lack of robustness is partly connected with the study of a later time period, but it mostly depends on the removal of a few outlying observations. Using LTS/RLS in combination with EBA clearly shows that EBA can be sensitive to outliers and that it is useful to use the techniques jointly.

\subsection{Effect size}

In this Section we study the distribution and the mean of the estimated Trust coefficients as the 20 switch variables are varied in all possible combinations of three, both for the small and for the full sample during the period 1990-2000. Figures 1 and 2 display the distribution of the estimates for Trust in the 1,140 regressions carried out for the two samples of countries. Figure 1 shows the distribution for the small sample.

\footnotetext{
${ }^{32}$ Our findings for Trust are broadly in line with those of Sturm and de Haan (2005) for other, "classic" variables thought to be robustly related to growth. Only Number of years open, Equipment investment, Latin-American dummy, Sub-Saharan dummy and Fraction Muslim meet the criteria of robustness and economic significance.

${ }^{33}$ This result is obtained from an alternative way of conducting this analysis, namely by excluding the four outliers identified in section 3.2 (in Table 4) one by one in order of importance. Compared to our method of identifying outliers uniquely for each regression, this method makes use of a slightly more homogenous sample since the same outliers are excluded in all regressions. In our view it is clearly more valuable to be able to identify outliers in each specification. The results of the analysis are in any case not sensitive to the choice of method, neither in terms of the quantitative results nor in terms of identified outliers (e.g., China and Ireland are the most important outliers in the large sample using the other method as well).
} 
Figure 1 The distribution of estimates for Trust: the small sample

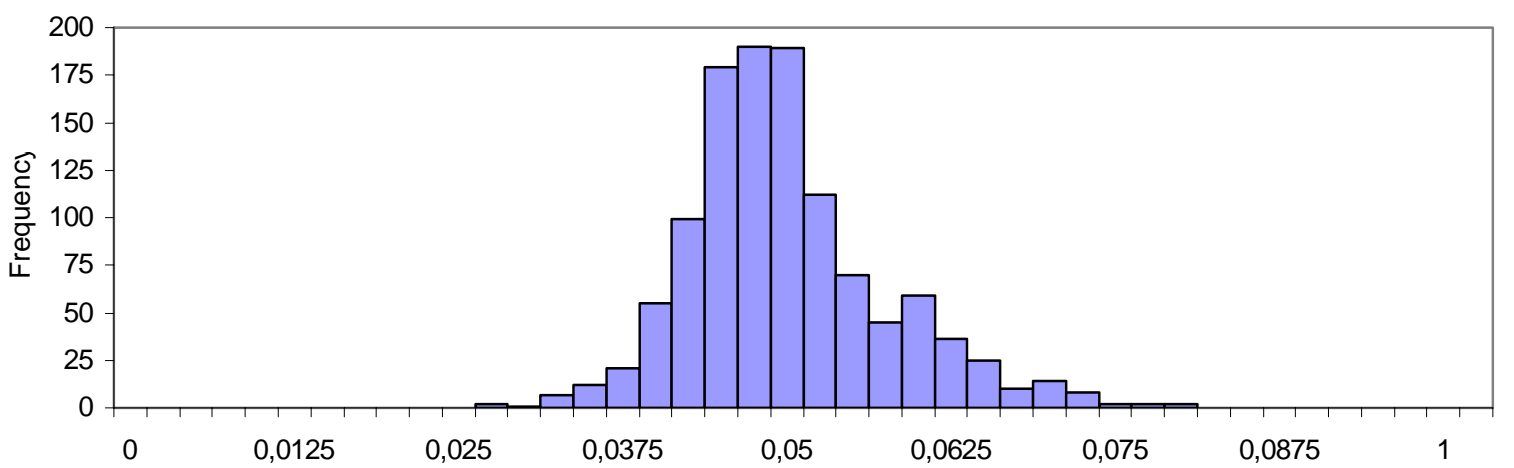

Min: 0.026. Max: 0.080. Mean: 0.049. Median: 0.048. Standard deviation: 0.008. Total number of estimates: 1140.

One might say that the relationship between Trust and Growth is fairly robust with respect to effect size for this sample. The spread around the mean is not excessive, and something like a bell shape can be observed. In comparison to what Beugelsdijk et al. find, we obtain a lower mean ( 0.049 instead of 0.061 ) but find only a small difference in the spread (a standard deviation of 0.008 instead of 0.011 ).

In Figure 2, the distribution for the large sample is shown. Now, a less robust relationship with respect to effect size can be detected. First, the spread is greater (the standard deviation is 0.018). Second, the shape of the distribution is much more uneven. However, the mean is quite similar $(0.049$ in the small and 0.044 in the large sample).

Figure 2 The distribution of estimates for Trust: the large sample

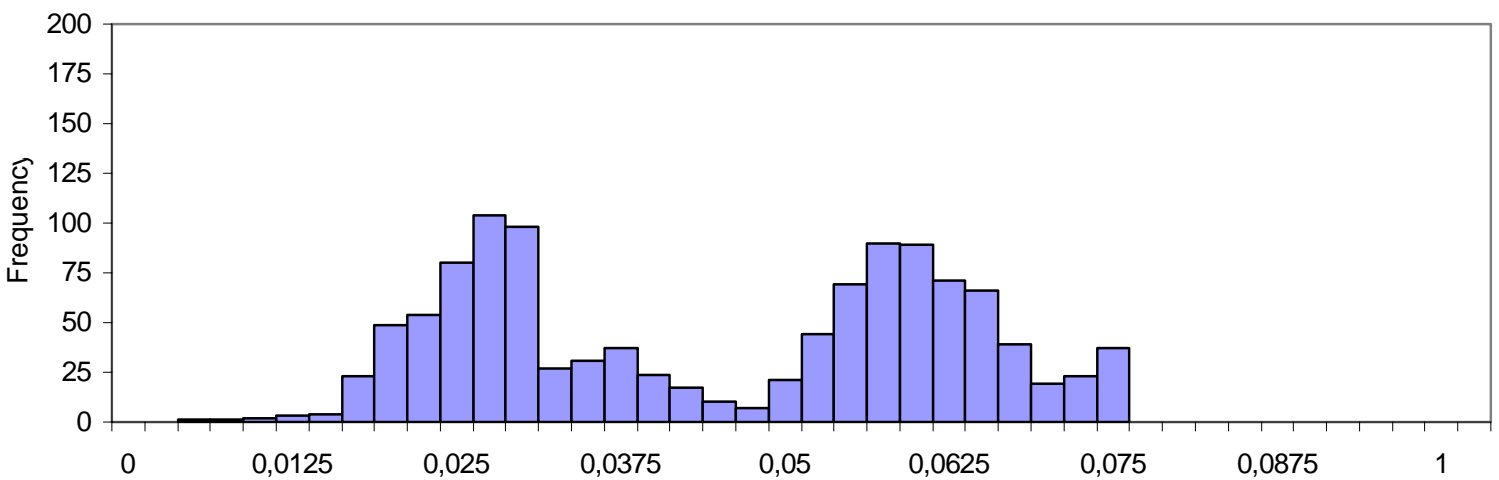

Min: 0.004 Max: 0.075. Mean: 0.044. Median: 0.047. Standard deviation: 0.018. Total number of estimates: 1140 .

How can the bimodality in Figure 2 be explained? We begin by taking a systematic look at how the mean of the Trust estimate changes when different switch variables are included in the regressions. Figure 3 shows the mean value of the Trust estimates from all regressions in which each specific switch variable is included. Some of the variables yield low trust estimates, most notably Real exchange rate distortion, Political assassinations, Outward orientation and Frankrom, whereas especially European language yields a high Trust estimate. Since China has missing values exactly for Real exchange rate distortion, Political assassinations, Outward orientation and Frankrom we suspect this country to be behind the peak with the larger estimates. 
Figure 3 Conditional mean effect size for Trust

- 90 percentile based on EBA estimates • Conditional mean from EBA - 10 percentile based on estimates from EBA

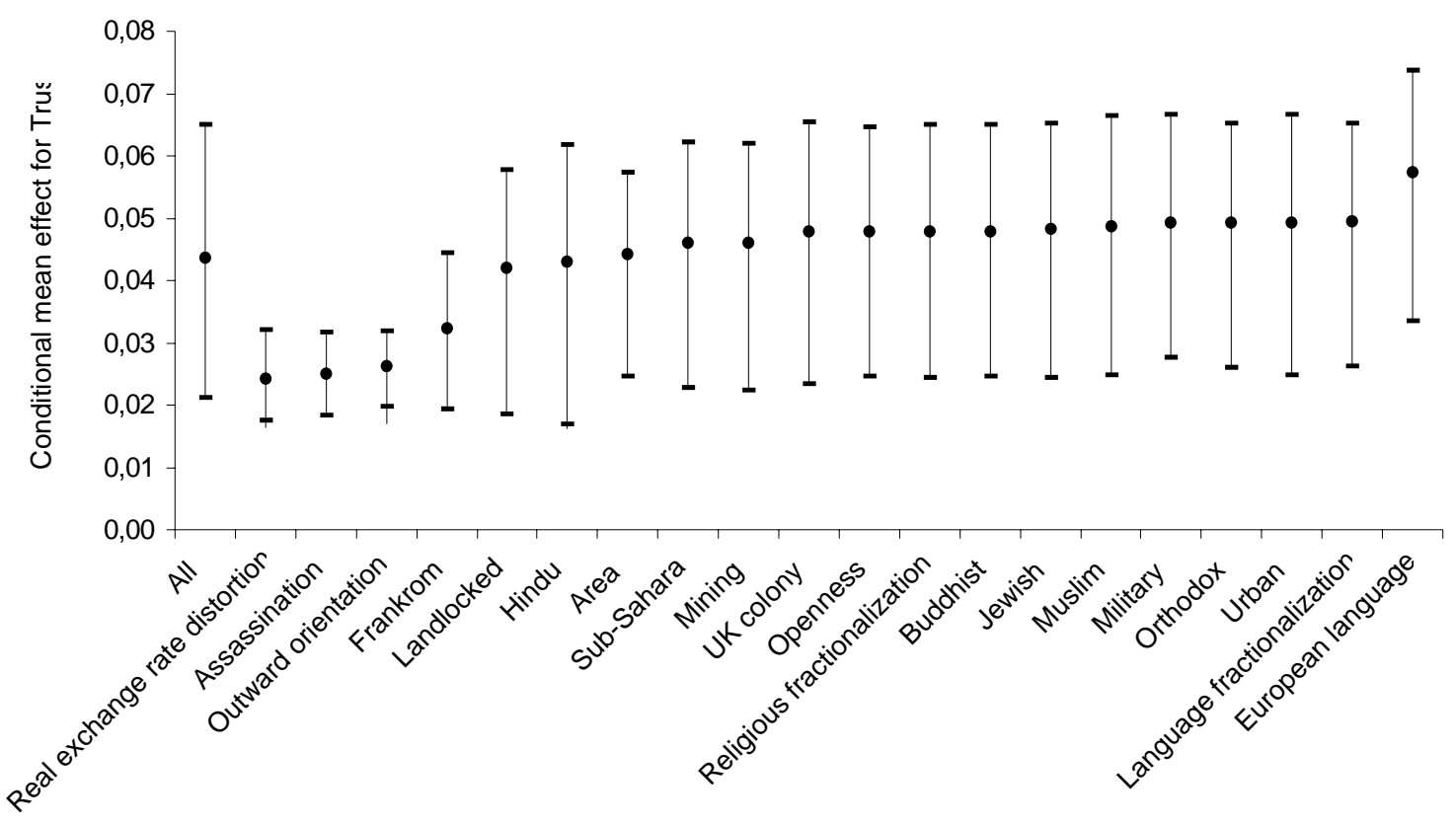

Figure 4 shows the distribution of Trust estimates from an EBA analysis which includes China but which excludes the four variables - Real exchange rate distortion, Political assassinations, Outward orientation and Frankrom - for which values are missing for China. The similarity to the right peak in Figure 2 is striking.

Figure 4 The distribution of estimates for Trust: the large sample when four switch variables with missing values for China have been excluded

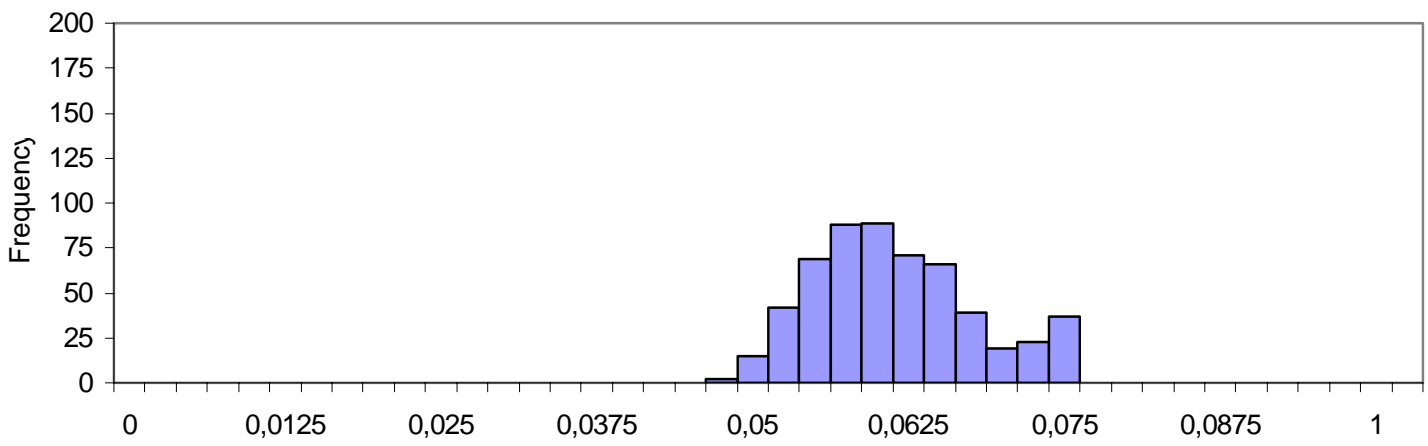

Min: 0.046. Max: 0.075. Mean: 0.060. Median: 0.059. Standard deviation: 0.006.Total number of estimates: 560.

Figure 5 instead shows the distribution of estimates for an EBA where China has been excluded from the sample of countries. This time the distribution of estimates is spread over a range of lower values, roughly in the same segment as the left peak in Figure 2. 
Figure 5 The distribution of estimates for Trust: the large sample, excluding China

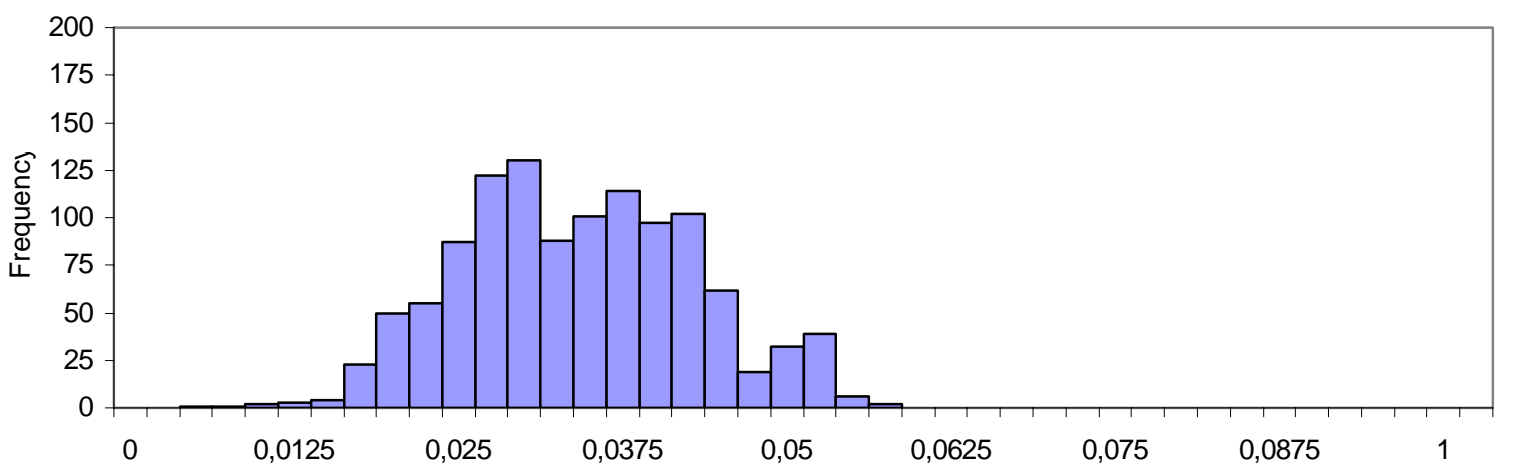

Min: 0.004. Max: 0.057. Mean: 0.033. Median: 0.033. Standard deviation: 0.009. Total number of estimates: 1,140 .

Together the results in this section underscore the impact of outliers on the estimates. ${ }^{34}$ When excluding China from the large sample, the bimodality pattern disappears, the distribution shifts leftward and the mean of the Trust estimates is reduced considerably (to about 0.03 ).

\section{Concluding remarks}

We have explored the relationship between generalized trust and economic growth, taking previous investigations further in several respects. Most importantly we have analysed a later time period, utilizing the new World Values Survey with data for more countries than has been available before, in an attempt to re-examine and extend previous results. We have looked at two time periods and two samples to be able to separate time and sample effects. Furthermore we have applied a robust estimation technique, LTS, in combination with RLS for inference, in order to see how outliers affect our results. We have also looked at robustness with respect to model specification, both by examining statistical significance (through EBA) and effect sizes. Lastly, LTS/RLS has been combined with EBA.

What have we found? Our basic OLS regression indicated, as in previous studies, a positive and statistically significant relationship between trust and economic growth. However, our robustness analysis revealed that there is more to this story. In fact, we found that i) when four outliers (China, Ireland, Nicaragua and Latvia, with China being the most extreme) were removed, the estimated coefficient was almost halved; ii) EBA clarified that statistical significance at the 5 percent level was obtained in only 29.3 percent (the small sample) and 49.3 percent (the large sample) of the 1,140 regressions, which is much lower than what has been found before; iii) when conducting EBA without outliers, robustness all but disappears: the trust coefficient is statistically significant at the 5 percent level in only 0.7 percent (the small sample) and 10.1 percent (the large sample) of all regressions; and iv) the distribution of estimated trust coefficients is more widespread compared with the previously studied sample of countries, which is explained by the influence of China, and the mean estimate is substantially reduced (approximately halved) when outliers are removed. Overall, the lack of robustness is partly connected with the study of a later time period, but mostly depends on the removal of a few outlying observations.

Connecting this to broader issues, an important rationale for a study of this kind is that economic growth is at the top of most policy agendas around the world, which makes it essential to better disentangle its determinants. Even though trust may not be robustly related to growth, it could still be important to some degree - and at least as important as many other "classic" variables.

\footnotetext{
${ }^{34}$ The distribution of the estimates from combining LTS and EBA (in Section 3.4) is very similar to the distribution in Figure 5.
} 
Acknowledgements The authors wish to thank Meredith Beechey, Christian Bjørnskov, Sören Blomquist, Jenny Nykvist, Panu Poutvaara, seminar participants at the Department of Economics, Uppsala University, and at the Ratio Institute, conference participants at the 2005 Meeting of the Public Choice Society in New Orleans and at the 2005 Meeting of the

European Public Choice Society in Durham and three anonymous referees for helpful comments and suggestions, and the Jan Wallander and Tom Hedelius Foundation (Elinder and Jordahl) and the Marcus and Amalia Wallenberg Memorial Fund Foundation (Berggren) for financial support. 


\section{Appendix}

Table A1 Variable specifications and descriptive statistics (1990-2000)

\begin{tabular}{|c|c|c|c|c|c|c|c|}
\hline Variable & Definition & \# obs & Mean & Std dev & Min & Max & Source \\
\hline Growth & $\begin{array}{l}\text { Annual growth rate in percent of real GDP (chain) per } \\
\text { capita, } 1990-2000: 100 *[(\text { Real GDP per capita } 2000 / \\
\left.\text { Real GDP per capita } 1990)^{1 / 10}-1\right] \\
\text { Taiwan: } 1990-1998\end{array}$ & 63 & 1.8 & 1.9 & -2.6 & 7.7 & Heston et al. (2002) \\
\hline Trust & $\begin{array}{l}\text { First value of trust } 1990-2000 \text {, i.e., the share that } \\
\text { agrees with the statement "most people can be } \\
\text { trusted" }\end{array}$ & 63 & 30.5 & 15.7 & 5.0 & 66.1 & $\begin{array}{l}\text { Inglehart et al. (2000); Zak and Knack (2001); Inglehart et al. (2004); } \\
\text { Latinobarómetro (2004) }\end{array}$ \\
\hline Schooling & Average years of schooling, 1990 & 63 & 6.7 & 2.6 & 2.2 & 12.0 & Barro and Lee (2001) \\
\hline $\begin{array}{l}\text { Real GDP per } \\
\text { capita }\end{array}$ & $\begin{array}{l}\text { Real GDP (chain) per capita, thousands of USD in } \\
1996 \text { constant prices, } 1990\end{array}$ & 63 & 10.2 & 7.6 & 0.7 & 26.5 & Heston et al. (2002) \\
\hline $\begin{array}{l}\text { Investment-good } \\
\text { price }\end{array}$ & $\begin{array}{l}\text { The PPP of investment divided by the exchange rate } \\
\text { times } 100,1990\end{array}$ & 63 & 79.0 & 33.5 & 12.5 & 177.7 & Heston et al. (2002) \\
\hline $\begin{array}{l}\text { Investment share } \\
\text { of GDP }\end{array}$ & $\begin{array}{l}\text { Total investment as share of GDP, average for } 1990- \\
2000\end{array}$ & 63 & 18.0 & 6.5 & 3.2 & 36.3 & Heston et al. (2002) \\
\hline Openness & $\begin{array}{l}\text { Exports plus imports divided by real GDP per capita, } \\
\text { in current prices, } 1990\end{array}$ & 63 & 57.4 & 29.0 & 15.0 & 154.6 & Heston et al. (2002) \\
\hline UK colony & $\begin{array}{l}\text { Dummy with value } 1 \text { if former UK colony and } 0 \\
\text { otherwise }\end{array}$ & 63 & 0.2 & 0.4 & 0 & 1.0 & $\begin{array}{l}\text { Persson and Tabellini (2003); http://www.britishempire.co.uk; } \\
\text { Encyclopaedia Britannica; Nationalencyklopedin [Swedish National } \\
\text { Encyclopedia] }\end{array}$ \\
\hline $\begin{array}{l}\text { Language } \\
\text { fractionalization }\end{array}$ & $\begin{array}{l}\text { One minus the Herfindal index of linguistic group } \\
\text { shares, } 2001\end{array}$ & 62 & 0.3 & 0.3 & 0 & 0.9 & Alesina et al. (2003) \\
\hline $\begin{array}{l}\text { Religious } \\
\text { fractionalization }\end{array}$ & $\begin{array}{l}\text { One minus the Herfindal index of religious group } \\
\text { shares, } 2001\end{array}$ & 63 & 0.4 & 0.2 & 0 & 0.9 & Alesina et al. (2003) \\
\hline Orthodox & Share of population that is Orthodox Christian, 2000 & 63 & 3.9 & 16.0 & 0 & 93.8 & $\begin{array}{l}\text { World Christian Database, http://www.worldchristiandatabase.org/wcd/; } \\
\text { population from Heston et al. (2002), for Taiwan from } \\
\text { http://www.census.gov/ipc/www/idbsum.html }\end{array}$ \\
\hline Muslim & Share of population that is Muslim, 2000 & 63 & 11.5 & 28.0 & 0 & 98.1 & Ditto \\
\hline Buddhist & Share of population that is Buddhist, 2000 & 63 & 1.9 & 7.7 & 0 & 55.7 & Ditto \\
\hline Hindu & Share of population that is Hindu, 2000 & 63 & 1.7 & 10.1 & 0 & 79.8 & Ditto \\
\hline Jewish & Share of population that is Jewish, 2000 & 62 & 0.3 & 0.5 & 0 & 3.1 & Ditto \\
\hline Sub-Sahara & $\begin{array}{l}\text { Dummy with value } 1 \text { if African country is located to } \\
\text { the south of the Sahara and } 0 \text { otherwise }\end{array}$ & 63 & 0.1 & 0.2 & 0 & 1.0 & \\
\hline
\end{tabular}




\begin{tabular}{|c|c|c|c|c|c|c|c|}
\hline Urban & Share of population in urban areas, 1990 & 62 & 60.7 & 19.1 & 11.2 & 96.4 & United Nations (2003) \\
\hline $\begin{array}{l}\text { European } \\
\text { language }\end{array}$ & $\begin{array}{l}\text { Fraction of a country's population that speaks English, } \\
\text { French, German, Portuguese or Spanish }\end{array}$ & 63 & 0.4 & 0.4 & 0 & 1.0 & Hall and Jones (1999); http://www.ethnologue.com \\
\hline Area & Million square kilometres & 63 & 1.2 & 2.4 & 0 & 10.0 & Central Intelligence Agency (2004) \\
\hline Mining & $\begin{array}{l}\text { Fraction of GDP produced in the mining and } \\
\text { quarrying sector, } 1988\end{array}$ & 58 & 0 & 0.1 & 0 & 0.5 & Hall and Jones (1999) \\
\hline $\begin{array}{l}\text { Outward } \\
\text { orientation }\end{array}$ & $\begin{array}{l}\text { Dummy with value } 1 \text { if outward orientation based and } \\
0 \text { otherwise, } 1988\end{array}$ & 55 & 0.4 & 0.5 & 0 & 1.0 & $\begin{array}{l}\text { King-Levine Dataset at } \\
\text { http://www.worldbank.org/research/growth/ddkile93.htm; primary source: } \\
\text { Syrquin and Chenery (1988) }\end{array}$ \\
\hline Assassination & $\begin{array}{l}\text { Number of political assassinations per billion } \\
\text { inhabitants, } 1980 \mathrm{~s}\end{array}$ & 54 & 0 & 0.2 & 0 & 1.3 & $\begin{array}{l}\text { King-Levine Dataset at } \\
\text { http://www.worldbank.org/research/growth/ddkile93.htm }\end{array}$ \\
\hline Frankrom & $\begin{array}{l}\text { Natural log of the Frankel-Romer forecasted trade } \\
\text { share, derived from a gravity model of international } \\
\text { trade that takes into account only country population } \\
\text { and geographical features }\end{array}$ & 50 & 2.6 & 0.7 & 0.9 & 4.0 & Persson and Tabellini (2003); primary source: Hall and Jones (1999) \\
\hline Military & Military expenditure as a share of GNI & 58 & 3.0 & 3.0 & 0 & 21.0 & World Bank (2001) \\
\hline $\begin{array}{l}\text { Real exchange- } \\
\text { rate distortion }\end{array}$ & Real exchange-rate distortion, index, 1991 & 54 & 114.6 & 33.7 & 70.0 & 248.0 & Levine and Renelt (1992); primary source: Dollar (1992) \\
\hline Landlocked & $\begin{array}{l}\text { Dummy with value } 1 \text { if landlocked country, i.e., } \\
\text { country without a coastline, and } 0 \text { otherwise }\end{array}$ & 63 & 0.1 & 0.4 & 0 & 1 & Central Intelligence Agency (2004) \\
\hline
\end{tabular}


Table A2 Values for Trust and Growth in the two samples (1990-2000)

The small sample includes the following 39 countries:

\begin{tabular}{|c|c|c|}
\hline Country & Trust & Growth \\
\hline Argentina & 23.3 & 4.3 \\
\hline Australia & 39.9 & 2.5 \\
\hline Austria & 31.8 & 1.8 \\
\hline Bangladesh & 21.0 & 2.8 \\
\hline Belgium & 33.2 & 1.8 \\
\hline Brazil & 6.7 & 1.5 \\
\hline Canada & 52.4 & 1.9 \\
\hline Chile & 22.7 & 4.9 \\
\hline Colombia & 10.0 & 0.9 \\
\hline Denmark & 57.7 & 2.0 \\
\hline Dominican Republic & 26.4 & 5.2 \\
\hline Finland & 62.7 & 1.6 \\
\hline France & 22.8 & 1.1 \\
\hline Germany & 37.8 & 1.6 \\
\hline Ghana & 23.0 & 1.4 \\
\hline United Kingdom & 43.6 & 1.9 \\
\hline Greece & 50.0 & 2.0 \\
\hline Iceland & 43.6 & 1.6 \\
\hline India & 34.3 & 4.0 \\
\hline Ireland & 47.4 & 6.4 \\
\hline Italy & 34.0 & 1.2 \\
\hline Japan & 41.7 & 1.1 \\
\hline Korea & 34.2 & 4.8 \\
\hline Mexico & 33.5 & 1.8 \\
\hline Netherlands & 54.9 & 2.2 \\
\hline New Zealand & 37.0 & 1.5 \\
\hline Norway & 65.1 & 2.8 \\
\hline Peru & 5.0 & 2.5 \\
\hline Philippines & 6.0 & 1.3 \\
\hline Portugal & 21.4 & 2.6 \\
\hline South Africa & 28.3 & -0.3 \\
\hline Spain & 33.8 & 2.2 \\
\hline Sweden & 66.1 & 1.3 \\
\hline Switzerland & 43.2 & 0.1 \\
\hline Taiwan & 42.0 & 5.7 \\
\hline Turkey & 10.0 & 1.8 \\
\hline Uruguay & 22.0 & 2.9 \\
\hline USA & 52.0 & 2.3 \\
\hline Venezuela & 14.0 & -0.8 \\
\hline
\end{tabular}

The large sample includes the following 24 additional countries: 


\begin{tabular}{lll}
\hline Country & Trust & Growth \\
\hline Algeria & 11.2 & -0.1 \\
Bolivia & 17 & 1.1 \\
China & 60.3 & 7.7 \\
Costa Rica & 11 & 1.8 \\
Czech Republic & 28 & 0.1 \\
Ecuador & 20 & -0.8 \\
Egypt & 37.9 & 2.6 \\
El Salvador & 14.6 & 2.3 \\
Guatemala & 28 & 0.8 \\
Honduras & 25 & -0.8 \\
Hungary & 24.6 & 0.8 \\
Indonesia & 51.6 & 2.5 \\
Jordan & 27.7 & 1.2 \\
Latvia & 19 & -2.6 \\
Nicaragua & 20 & -2.4 \\
Pakistan & 30.8 & 1.4 \\
Panama & 25 & 2 \\
Paraguay & 23 & -0.6 \\
Poland & 34.5 & 3.4 \\
Romania & 16.1 & -1.1 \\
Slovakia & 23 & 1.9 \\
Slovenia & 17.5 \\
Uganda & & \\
Zimbabwe & 2.6 & \\
\hline & & \\
\hline
\end{tabular}

\section{References}

Alesina A, Devleeschauwer A, Easterly W, Kurlat S, Wacziarg R (2003) Fractionalization. Journal of Economic Growth 8: $155-194$

Alesina A, La Ferrara E (2002) Who trusts others? Journal of Public Economics 85: 207-234

Barro, RJ (1991) Economic growth in a cross section of countries. Quarterly Journal of Economics 106: 407-443

Barro, RJ (1997) Determinants of economic growth: a cross-country empirical study. The MIT Press, Cambridge, Massachusetts

Barro, RJ, Lee, J-W (2001) International data on educational attainment: updates and implications. Oxford Economic Papers 53: 541-563

Berggren N, Jordahl H (2006) Free to trust: economic freedom and social capital. Kyklos 29: 141-169

Beugelsdijk S, de Groot HLF, Schaik ABTM van (2004) Trust and economic growth: a robustness analysis. Oxford Economic Papers 56: 118-134

Bjørnskov C (2007) Determinants of generalized trust: a cross-country comparison. Public Choice 130: 1-21

Buchan N, Croson R (2004) The boundaries of trust: own and others' actions in the US and China. Journal of Economic Behavior and Organization 55: 485-504

Central Intelligence Agency (2004) The world factbook 2004. Central Intelligence Agency, Washington, District of Columbia

Dasgupta P, Sergaldin I (eds) (2000) Social capital: a multifaceted perspective. World Bank, Washington, District of Columbia

de la Fuente A, Domenech R (2006) Human capital in growth regressions: how much difference does data quality make? Journal of the European Economic Association 4: 1-36

Dollar D (1992) Outward-oriented developing economies really do grow more rapidly: evidence from 95 LDC's, 1976-85. Economic Development and Cultural Change 40: 523-544

Durlauf SN, Quah, DT (1999) The new empirics of economic growth. In: Taylor JB, Woodford M (eds) Handbook of macroeconomics, vol. 1. North Holland, Amsterdam, pp 235-308 
Fernandez C, Ley E, Steel MFJ (2001) Model uncertainty in cross-country growth regressions. Journal of Applied Econometrics 16: 563-576

Florax RJGM, de Groot HLF, Heijungs R (2002) The empirical economic growth literature: robustness, significance and size. Tinbergen Institute discussion paper 2002-040/03, Tinbergen Institute, Amsterdam and Rotterdam

Glaeser EL, Laibson DI, Scheinkman JA, Soutter CL (2000) Measuring trust. Quarterly Journal of Economics 115: 811-846

Hall, RE, Jones CI (1999) Why do some countries produce so much more output per worker than others? Quarterly Journal of Economics 114: 83-116

Heston A, Summers R, Aten B (2002) Penn world table version 6.1. Center for International Comparisons at the University of Pennsylvania (CICUP)

Holz C (2003) How reliable are Chinese output and economic growth statistics? The China Quarterly 173: 122-163

Hubert M, Rousseeuw PJ, Van Aelst S (2004) Robustness. In: Sundt B, Teugels J (eds) Encyclopedia of actuarial sciences. John Wiley \& Sons, New York, New York, pp. 1515-1529

Inglehart, R (1999) Trust, well-being and democracy. In: Warren, M (ed) Democracy and trust. Cambridge University Press, Cambridge, pp 88-120

Inglehart R et al. (2000) World values surveys and European values surveys, 1981-1984, 1990-1993, and 1995-1997. ICPSR study 2790, Inter-University Consortium for Political and Social Research, Institute for Social Research, Ann Arbor, Michigan

Inglehart R, Basañez M, Diez-Medrano J, Halman L, Luijkx R (2004) Human beliefs and values: a cross-cultural sourcebook based on the 1999-2002 values surveys. Siglo XXI Editores, Mexico City

King A (1991) Kuan-ksi and network building: a sociological interpretation. Daedalus 120: 63-84.

Knack S, Keefer P (1997) Does social capital have an economic payoff? A cross-country investigation. Quarterly Journal of Economics 112: 1251-1288

Knack S, Zak PJ (2002) Building trust: public policy, interpersonal trust, and economic development. Supreme Court Economic Review 10: 91-107

Krueger AB, Lindahl, M (2001) Education for growth: why and for whom? Journal of Economic Literature 39: 1101-1136.

La Porta R, Lopez-de-Silanes F, Schleifer A, Vishny RW (1997) Trust in large organizations. American Economic Review 87: $333-338$

Latinobarómetro (2004) http://www.latinobarometro.org

Leamer EE (1985) Sensitivity analyses would help. American Economic Review 75: 308-313

Levine R, Renelt D (1992) A sensitivity analysis of cross-country growth regressions. American Economic Review 82: 942 963

Lorgelly PK, Owen PD (1999) The effect of female and male schooling on economic growth in the Barro-Lee model. Empirical Economics 24: 537-557

Maddison A (1998) Chinese economic performance in the long run. OCED, Paris

McCloskey DN (1985) The loss function has been mislaid: the rhetoric of significance tests. American Economic Review 75: 201-205

McCloskey DN, Ziliak ST (1996) The standard error of regressions. Journal of Economic Literature 34: 97- 14

Persson T, Tabellini G (2003) The economic effects of constitutions. The MIT Press, Cambridge, Massachusetts

Rawski TG (2001) What is happening to China's GDP statistics? China Economic Review 12: 347-355

Ren R (1997) China's economic performance in an international perspective. OECD, Paris

Rousseeuw PJ (1984) Least median of squares regression. Journal of the American Statistical Association 79: 550-559

Rousseeuw PJ, Leroy AM (1987) Robust regression and outlier detection. John Wiley \& Sons, New York, New York

Rousseeuw PJ, Van Driessen K (2006) Computing LTS regression for large data sets. Data Mining and Knowledge Discovery 12: 29-45

Sala-i-Martin X (1997) I just ran two million regressions. American Economic Review 87: 178-183

Sala-i-Martin X, Doppelhofer G, Miller, RI (2004) Determinants of long-term growth: a Bayesian averaging of classical estimates (BACE) approach. American Economic Review 94: 813-835

Sturm, J-E, de Haan J (2001) How robust is the relationship between economic freedom and growth? Applied Economics 33: 839-844

Sturm, J-E, de Haan J (2002) How robust is Sala-i-Martin's robustness analysis? Mimeo. Department of Economics, University of Groningen, Groningen, The Netherlands

Sturm, J.-E. and de Haan, J. (2005) Determinants of long-term growth: new results applying robust estimation and extreme bounds analysis. Empirical Economics 30: 597-617

Syrquin M, Chenery H (1998) Patterns of development, 1950-1983. World Bank discussion paper 41, World Bank, Washington, District of Columbia

Temple J (1999) The new growth evidence. Journal of Economic Literature 37: 112-156

Temple J (2001) Generalizations that aren't? Evidence on education and growth. European Economic Review 45: 905-918

United Nations (2003) World urbanization prospects: the 2003 revision. United Nations, New York, New York

Uslaner, EM (2002) The moral foundations of trust. Cambridge University Press, Cambridge

Verboven S, Hubert M (2005) LIBRA: A MATLAB library for robust analysis. Chemometrics and Intelligent Laboratory Systems 75: $127-136$

World Bank (2001) World development indicators CD-rom. World Bank, Washington, District of Columbia

Zak PJ, Knack S (2001) Trust and growth. Economic Journal 111: 295-321

Zaman A, Rousseeuw PJ, Orhan M (2001) Econometric applications of high-breakdown robust regression techniques. Economics Letters 71: 1-8.

Ziliak ST, McCloskey DN (2004) Size matters: the standard error of regressions in the American Economic Review. Econ Journal Watch 1: 331-358, http://www.econjournalwatch.org/pdf/ZiliakMcCloskeyAugust2004.pdf 